\title{
Identification of the sentinel lymph node using hemosiderin in locally advanced breast cancer
}

\section{Identificação do linfonodo sentinela utilizando hemossiderina em casos de câncer de mama localmente avançado}

Paulo Henrique Walter de Aguiar, ACbC-Ce1; Ranniere Gurgel Furtado de Aquino ${ }^{1,4}$; Mayara Mala Alves²; Julio Marcus Sousa

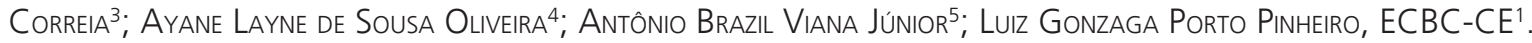

\begin{abstract}
A B S T R A C T
Objective: to verify the agreement rate in the identification of sentinel lymph node using an autologous marker rich in hemosiderin and 99 Technetium (Tc99) in patients with locally advanced breast cancer. Methods: clinical trial phase 1, prospective, non-randomized, of 18 patients with breast cancer and clinically negative axilla stages $T 2=4 \mathrm{~cm}, T 3$ and T4. Patients were submitted to sub-areolar injection of hemosiderin 48 hours prior to sentinel biopsy surgery, and the identification rate was compared at intraoperative period to the gold standard marker Tc99. Agreement between methods was determined by Kappa index. Results: identification rate of sentinel lymph node was $88.9 \%$, with a medium of two sentinel lymph nodes per patients. The study identified sentinel lymph nodes stained by hemosiderin in $83.3 \%$ patients ( $n=15)$, and, compared to Tc99 identification, the agreement rate was $94.4 \%$. Conclusion: autologous marker rich in hemosiderin was effective to identify sentinel lymph nodes in locally advanced breast cancer patients.
\end{abstract}

Keywords: Breast Neoplasms. Sentinel Lymph Node Biopsy. Hemosiderin. Technetium.

\section{INTRODUCTION}

S entinel lymph node (SL) is the first lymph node that receives lymphatic drainage of a particular primary tumor location'. Cabanas1, in 1977, studied penile adenocarcinoma patients and stablished for the first time the technique to perform biopsy of sentinel lymph node (BSL). In order to improve identification rate of SB in melanoma patients, Krag et al. ${ }^{2}$, in 1993, used Technetium 99 (Tc99) successfully. Later, in 1994, Giuliano et al. ${ }^{3}$, using patent blue as marker for SL in breast cancer, introduced the concept of biopsy of SL (BSL) in daily practice. In 2003, Veronesi et al. ${ }^{4}$ stated that BSL is a safe and accurate method to evaluate axillary metastasis in women with small breast tumors. Nowadays, BSL replaced axillary lymphadenectomy at initial breast cancer staging in patients with clinically negative axilla ${ }^{5}$.

The association of Tc99 and patent blue marker was more accurate to identify $B S L^{6,7}$. Other markers have been used in the identification of SB during surgical procedure, such as methylene blue, patent blue and isosulfan ${ }^{8}$. However, those substances, in a recent literature review, present a high number of hypersensitivity reactions $s^{9,10}$. Patent blue may cause subtle adverse effects, such as cutaneous rash, or even severe, such as anaphylaxis ${ }^{11,12}$. Methylene blue may also cause severe reactions, including skin and fat necrosis at the site of injection ${ }^{13}$. Anaphylactic reactions with isosulfan and patent blue in patients submitted to BSL vary from $0.6 \%$ to $2.7 \%{ }^{14}$.

In 2009, Pinheiro et al. ${ }^{15}$ proved, in animal experimental study, the efficiency of hemosiderin, a product of hemoglobin degradation and a protein usually found in lysosomes of histiocytes and in Kupfer cells, as an autologous marker of BSL in bitches breasts. In that study, association of hemosiderin and Tc99 has shown similar results of the association of Tc99 and patent blue in BSL. Experimentally, hemosiderin proved to be a new

1 - Federal University of Ceará, Medical Surgical Sciences Post-Graduate Program, Fortaleza, CE, Brazil. 2 - Federal University of Ceará, Biotechnology Post-Graduate Program (RENORBIO), Fortaleza, CE, Brazil. 3 - SONIMAGEM, Image Diagnosis, Fortaleza, CE, Brazil. 4 - Fortaleza University School of Medicine, Fortaleza, CE, Brazil. 5 - Ceará Federal University, Walter Cantídio University Hospital, Fortaleza, CE, Brazil. 
marker without adverse reactions and an alternative to current markers.

In 2015, Vasques et al. ${ }^{16}$ introduced the studies with hemosiderin in initial human breast cancer (T1/ T2) with clinically negative axilla, and success (identification) and agreement rates of $100 \%$ compared to gold standard (Tc99). In view of those results, the present study proposal was to evaluate the efficacy of hemosiderin to identify sentinel lymph node in patients with locally advanced breast cancer ( $\mathrm{T} 2>4 \mathrm{~cm} / \mathrm{T} 3 / \mathrm{T} 4)$, compared to TC99 gold standard test.

\section{METHODS}

Phase 1 clinical trial, prospective, non-randomized, that studied women with locally advanced breast cancer. Surgical procedures were performed at Maternidade Escola Assis Chateaubriand (MEAC) and Walter Cantídio University Hospital by a single surgeon from January to December 2016. The study was approved by the Research Ethical Committee of Hospital Universitario Walter Cantidio of Federal University of Ceará, \# 2.032.200. Each patient was informed and signed a Free Consent Form to participate.

\section{Sampling and selection criteria}

Sample included 18 women, non-randomized, selected at Mastology Ambulatory of Maternidade Escola Assis Chateaubriand (MEAC), with indication of BSL. Patients were 18 to 75 years old, and had breast cancer with pathologic proved diagnosis, stages II $(\geq 4 \mathrm{~cm})$, III and IV and clinically negative axilla before neoadjuvant chemotherapy. Patients with inflammatory breast cancer, pregnant women, those who had received any chemotherapy or neoadjuvant radiotherapy or that had been submitted to axillary surgery and/or previous incisional biopsy that could have compromised breast lymphatic drainage were excluded.

One week before the beginning of the study, all participants were submitted to clinical evaluation and pre-operatory laboratory tests, being fit for surgical procedure. Iron profile was also previously evaluated by complete blood count, serum iron, serum ferritin, transferrin saturation and iron total ligand capacity.

\section{Preparation of marker rich in hemosiderin}

Hemosiderin preparation for use at the study was obtained in a $16 \mathrm{ml}$ of peripheral blood sample 48 hours before surgery. Collected blood was maintained in two aseptic BD Vacutainer ${ }^{\circledR}$ tubes containing buffered Sodium Citrate. Next, the tubes were centrifuged at $2000 \mathrm{rpm}$ at $22^{\circ} \mathrm{C}$ for ten minutes. Centrifuged material were distributed in three layers: the superior and intermediate (serum) were discharged and the inferior (red cells) was diluted with equal volume that was removed, and manually homogenized with saline in a laminar flow chamber. The obtained solution was again centrifuged (3800rpm for three minutes) and two layers were produced. The first was discharged and the volume was replaced by double distilled water at the laminar flow chamber, causing hemolysis of the packed red cells. After the third and last centrifugation (3800rpm for three minutes), it was obtained a single layer of lysate red cells, rich in hemosiderin, suspended in a reddish liquid. Sterility control was verified by the use of bacterial and fungus cultures.

Four milliliters of marker rich in hemosiderin was injected ambulatorily; patient was kept in dorsal decubitus, under local anesthesia with $2 \%$ lidocaine without adrenalin at the external breast periareolar region (at $3 \mathrm{~h}$ position), using a single injection with aseptic technique (Figures $1 \mathrm{~A}$ and $1 \mathrm{~B}$ ).

Patients were admitted and followed up for collateral effects for 24 hours. Before surgical procedure, each patient received a subareolar intradermal infection of $0.2 \mathrm{ml}$ of Tc99, and, following local anesthesia and sedation, were submitted to surgical procedure.

\section{Procedure: biopsy of sentinel lymph node (BSL)}

Patients were submitted to $B S L$, incising the axillary fold, guided by gamma-probe. Dissection proceeded until identification of maximal point of Tc99 captation, and marked lymph node was identified and its color was noted (Figures 2A and 2B). After lymph node removal, Tc99 intensity detection of each was verified by gamma-probe. Those data were registered in a proper sheet for posterior analysis. 

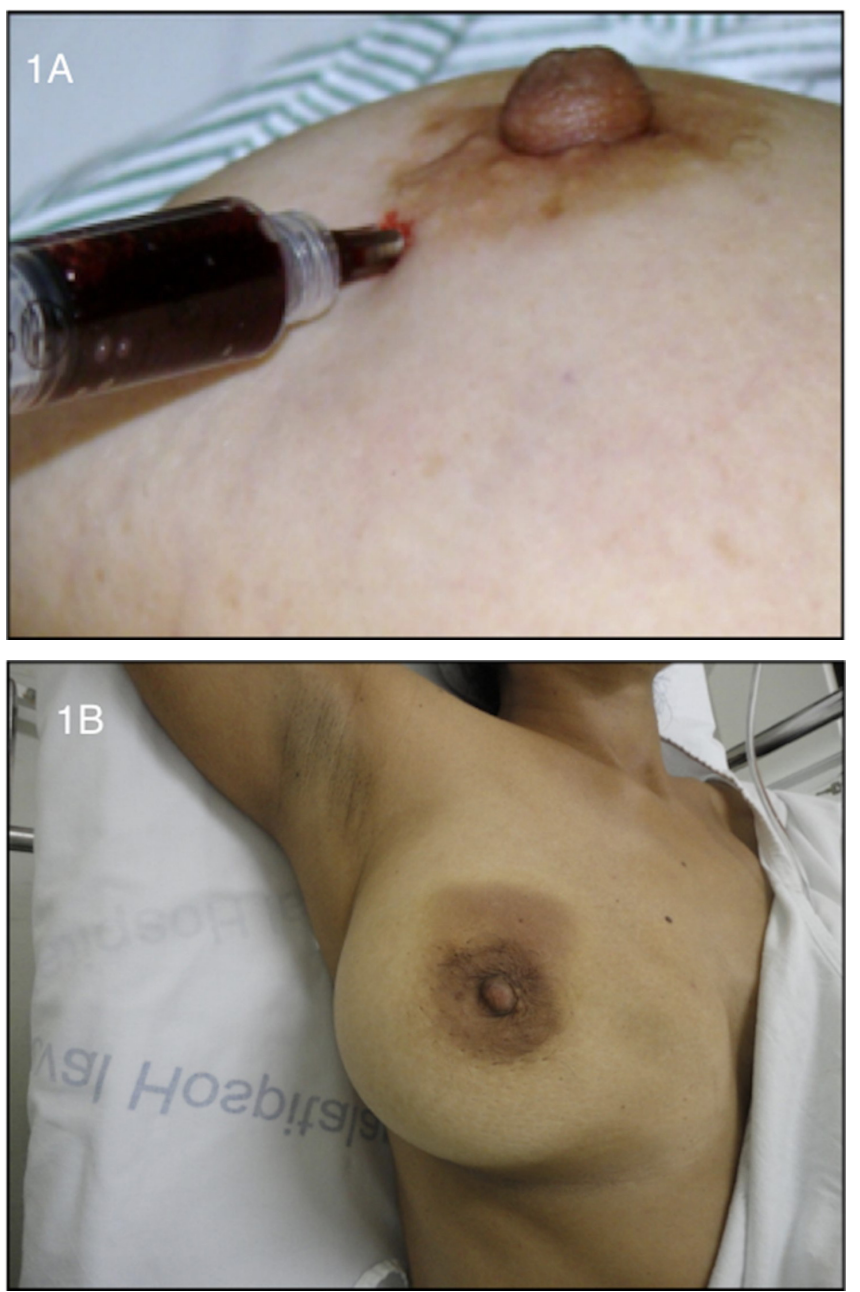

Figure 1. A ) Subareolar injection of hemosiderin; B) Site post-injection of hemosiderin (hematoma post-injection).

All surgical samples were submitted to pathologic and immune histochemical studies. Patients were followed up during all procedure, since hemosiderin injection until post-operatory and consultation after 15 and 30 days of surgery.

\section{Statistical analysis}

Data were evaluated by Kappa Coefficient Agreement. $\mathrm{P}$ values were determined by Fisher exact test. $\mathrm{P}$ values $\leq 0.05$ were considered statistical significant.

\section{RESULTS}

Eighteen patients were submitted to BSL with hemosiderin according to described method. Mean age of patients was 48.2 years and $63.7 \%$ were pre-meno- pausal. At histology, all patients had invasive tumor, 17 with ductal tumor. T3 staging was the most frequent and $55 \%$ of patients had a positive axillary study at pathology (Table 1). There were no adverse effects and/ or allergic reactions, surgical infection or toxicity in all patients submitted to BSL with hemosiderin in this study.

At surgery, marking with hemosiderin was extremely satisfactory for visual identification and differentiation of SL from all other axillary lymph nodes (Figure 3).

Efficacy of BSL with hemosiderin was compared to gold-standard technique with Tc99 and the results were satisfactory. Identification rate of SL was $88.9 \%$ and a medium of two SB were found by patient. The study identified SL marked with hemosiderin in 83.3\% of patients ( $n=15)$ and, compared to Tc99 identification, agreement was observed in $94.4 \%$ of studied patients, Kappa index $=0.77$ and $p=0.001$ (Figure 4).

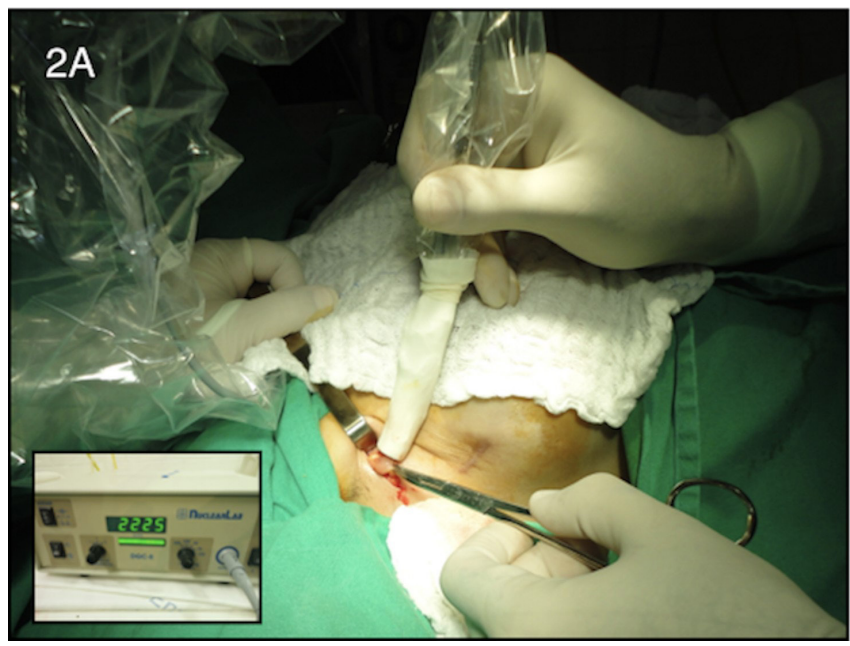

\section{$2 B$}

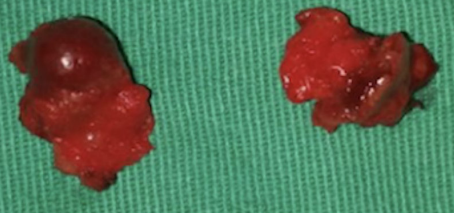

Figure 2. A) Intraoperative identification of sentinel lymph node using Gamma-Probe; B) Sentinel lymph nodes strongly stained with hemosiderin. 
Table 1. Clinical and pathological data of studied patients and respective analyzed tumors.

\begin{tabular}{lc}
\hline Characteristics & Value \\
\hline Age (medium years) & $48.2(33-69 \pm 11)$ \\
\hline Menopausa status & $\mathrm{n}=12(66.7 \%)$ \\
Pre-menopausa & $7(33.3 \%)$ \\
Post-menopausa & $18(100 \%)$ \\
\hline Invasion Grade & $0(0 \%)$ \\
Invasive carcinoma & \\
Carcinoma in situ & $11(60.5 \%)$ \\
\hline Location of primary tumor & $3(16.5 \%)$ \\
External superior quadrant & $2(11.1 \%)$ \\
Internal superior quadrant & $1(5.5 \%)$ \\
External inferior quadrant & $1(5.5 \%)$ \\
Internal inferior quadrant & \\
Central & \\
\hline Tumor size & $1(5.4 \%)$ \\
T2=4cm & \\
T3 & $3(16.6 \%)$ \\
14(77.8\%) & \\
T4C & $10(55.5 \%)$ \\
\hline Lymph node status & $8(44.5 \%)$ \\
Negative sentinel lymph node & \\
Positive sentinel lymph node & \\
Histologic subtype & \\
Ductal & \\
Lobular & \\
\hline & \\
&
\end{tabular}

\section{DISCUSSION}

At medical literature, studies performed in several conditions showed adequate agreement with our results. Krag et al. study ${ }^{2}$ analyzed 443 patients and identification rate was $93 \%$. Albertini et al. ${ }^{17}$ associated two techniques (patent blue and radiocolloid) and observed an increase of SL identification rate to $92 \%$ with predictive value of $100 \%$. Veronesi et al.4 showed a $98.2 \%$ identification rate with $2.5 \%$ of false negative. Possible failures of identification rate may be caused by inherent technical, physician and patients factors.

When patients submitted to neoadjuvant chemotherapy followed by BSL are studied, iden-
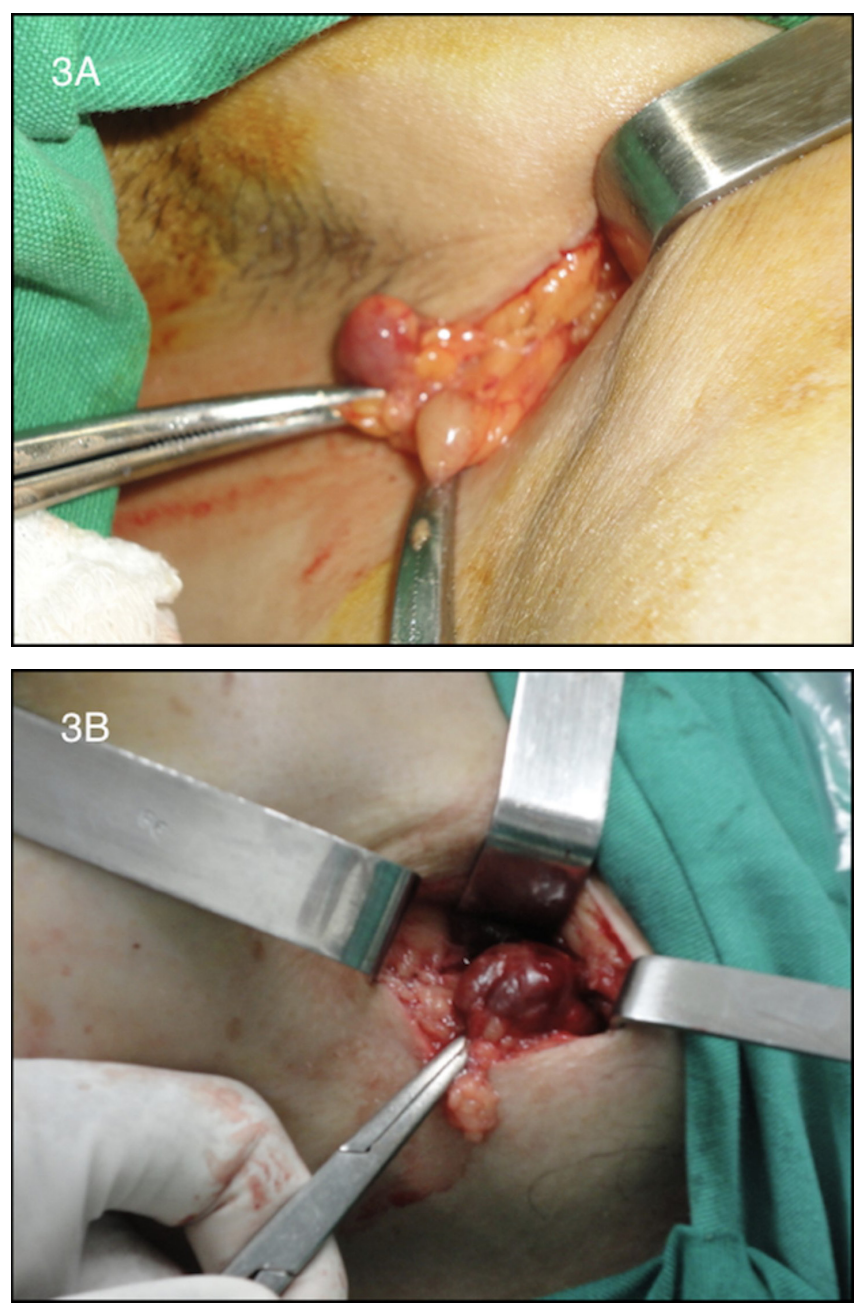

Figure 3. A) Macroscopic stained SL with hemosiderin and another non-stained axillary lymph node; B) Intraoperative aspect of strongly stained SB.

tification rate may be lower due to chemotherapy effects. Breslin et al. study ${ }^{18}$ found an identification rate of $84 \%$. Other studies showed identification rates varying from $85 \%$ to $98 \%$ (as quoted by Xing et al. study ${ }^{19}$ ). Jones et al. ${ }^{20}$ compared BSL before and after neoadjuvant chemotherapy and found a respective rate of identification of $100 \%$ and $80.6 \%$, and a higher false negative rate in post-chemotherapy group (11\%). In the series studied by Cox et al. ${ }^{21}$, including 89 patients with locally advanced breast cancer, stratified in two groups (positive and negative axilla), it was observed that BSL before chemotherapy had an adequate accuracy for negative axilla. Papa et al. study 22 compared sentinel lymph node biopsy before and after chemotherapy and the iden- 

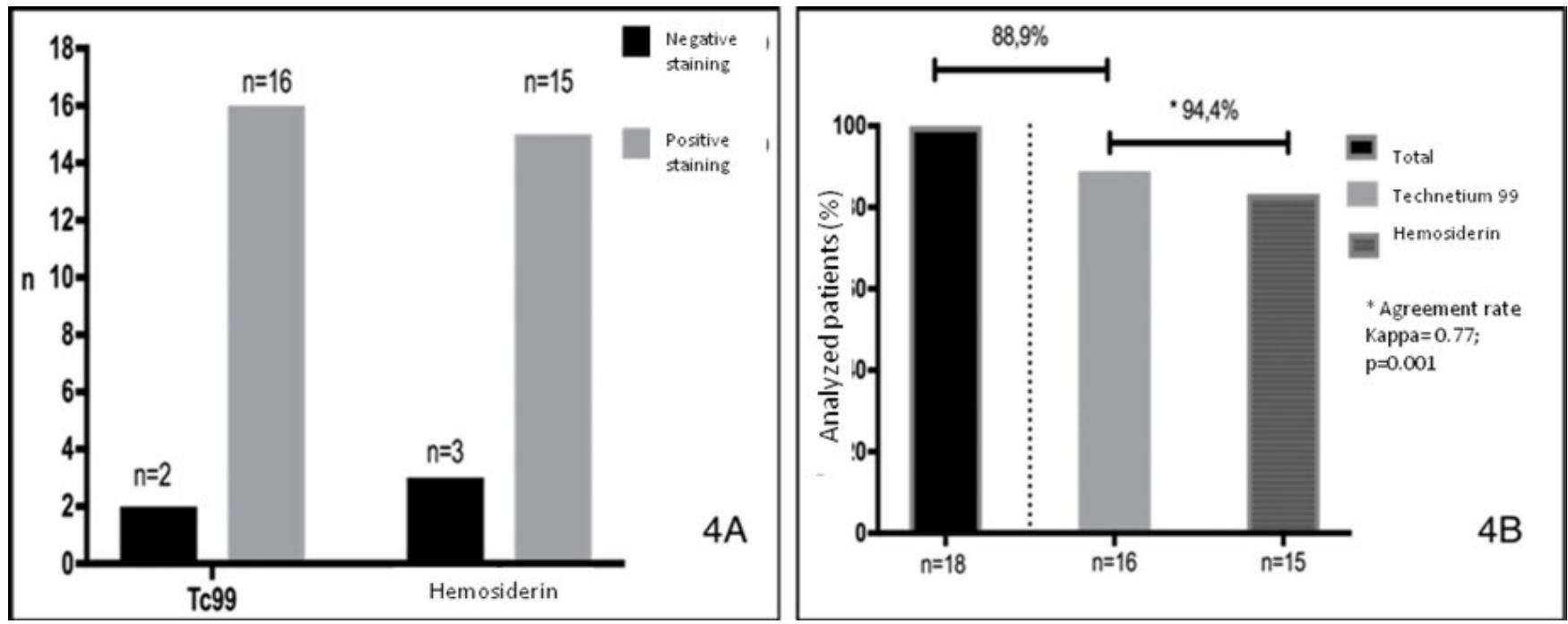

Figura 4. A) Hemosiderin and TC99-stained SL per patients; B) Agreement rate of hemosiderin and Tc99 with statistical significance.

tification rate was $98.8 \%$ and $87 \%$, respectively.

Other markers for SL have been studied and the supermagnetic iron nanoparticle had an identification rate of $77 \%$, inferior to those observed with the use of hemosiderin as autologous marker in 14 patients submitted to BSL that showed an identification rate of $100 \%$ and agreement rate of $100 \%^{16}$. In our series of 18 patients, in 16, SL was identified using radiocolloid and in 15 using hemosiderin, with an agreement rate of $94.4 \%$.In only one patient, there was discrepancy (identification of lymph node by radiopharmaceutical agent and not by hemosiderin). Probable causes include size of hemosiderin molecule, since big molecules may not reach lymphatic vessels, preventing migration to lymph node.

It is observed a tendency to avoid the use of radioisotope and patient exposure to radiation, and of patent blue, due to potentially severe adverse reactions. In facilities with adequate nuclear medicine departments, costs are elevated (particularly of gamma-probe) and radioisotope half-life is short. The studied autologous marker was safely injected 48 hours before surgery, without any adverse reaction.

Our study suggests that the use of hemosiderin as an autologous marker is useful at daily clinical practice, to identify sentinel lymph node in locally advanced breast tumors.

\section{R E S U M O}

Objetivo: verificar a taxa de concordância na identificação do linfonodo sentinela utilizando um marcador autólogo rico em hemossiderina e o Tecnécio 99 (Tc99) em casos de câncer de mama localmente avançados. Métodos: ensaio clínico fase 1, do tipo prospectivo, não randomizado, em 18 pacientes portadoras de câncer de mama com axila clinicamente negativa em estádio T2=4cm, T3 e T4. As pacientes foram submetidas à injeção sub-areolar de um marcador autólogo rico em hemossiderina 48 horas antes do procedimento cirúrgico para biópsia do linfonodo sentinela, e sua taxa de identificação foi comparada, no intraoperatório, com o marcador radioativo Tc99 (padrão-ouro). A concordância entre os métodos foi estabelecida pelo índice de Kappa. Resultados: a taxa de identificação do linfonodo sentinela foi de $88,9 \%$, com uma média de dois linfonodos sentinelas por paciente. O estudo identificou os linfonodos sentinelas corados com hemossiderina em $83,3 \%$ dos casos $(n=15)$, quando comparados com a taxa de identificação do Tc99, tendo sido observada concordância em 94,4\% dos casos estudados. Conclusão: o marcador autólogo rico em hemossiderina se mostrou eficaz na identificação do linfonodo sentinela em casos de câncer de mama localmente avançado.

Descritores: Neoplasias da Mama. Biópsia de Linfonodo Sentinela. Hemossiderina. Tecnécio. 


\section{REFERENCES}

1. Cabanas RM. An approach for the treatment of penile carcinoma. Cancer. 1977;39(2):456-66.

2. Krag DN, Weaver DL, Alex JC, Fairbank JT. Surgical resection and radiolocalization of the sentinel lymph node in breast cancer using a gamma probe. Surg Oncol. 1993;2(6):335-9; discussion 340.

3. Giuliano AE, Kirgan DM, Guenther JM, Morton DL. Lymphatic mapping and sentinel lymphadenectomy for breast cancer. Ann Surg. 1994;220(3):391-8; discussion 398-401.

4. Veronesi U, Paganelli G, Viale G, Luini A, Zurrida S, Galimberti $V$, et al. A randomized comparison of sentinel-node biopsy with routine axillary dissection in breast cancer. N Engl J Med. 2003;349(6):546-53.

5. Lyman GH, Temin S, Edge SB, Newman LA, Turner RR, Weaver DL, Benson AB 3rd, Bosserman LD, Burstein HJ, Cody H 3rd, Hayman J, Perkins CL, Podoloff DA, Giuliano AE; American Society of Clinical Oncology Clinical Practice. Sentinel lymph node biopsy for patients with early-stage breast cancer: American Society of Clinical Oncology clinical practice guideline update. J Clin Oncol. 2014;32(13):1365-83.

6. Rutgers EJ. Guidelines to assure quality in breast cancer surgery. Eur J Surg Oncol. 2005;31(6):56876.

7. Straver ME, Meijnen $P$, van Tienhoven $G$, van de Velde CJ, Mansel RE, Bogaerts J, et al. Sentinel node identification rate and nodal involvement in the EORTC 10981-22023 AMAROS trial. Ann Surg Oncol. 2010;17(7):1854-61.

8. Thill $M$, Kurylcio $A$, Welter $R$, van Haasteren $V$, Grosse B, Berclaz G, et al. The Central-European SentiMag study: sentinel lymph node biopsy with superparamagnetic iron oxide (SPIO) vs. radioisotope. Breast. 2014;23(2):175-9.

9. Kalimo K, Jansén $C T$, Kormano M. Sensitivity to Patent Blue dye during skin-prick testing and lymphography. A retrospective and prospective study. Radiology. 1981;141(2):365-7.

10. Mertes PM, Malinovsky JM, Mouton-Faivre C, Bonnet-Boyer MC, Benhaijoub A, Lavaud F, et al. Anaphylaxis to dyes during the perioperative period: reports of 14 clinical cases. J Allergy Clin Immunol.
2008;122(2):348-52.

11. Haque RA, Wagner A, Whisken JA, Nasser SM, Ewan PW. Anaphylaxis to patent blue V: a case series and proposed diagnostic protocol. Allergy. 2010;65(3):396-400.

12. Wöhrl S, Focke $M$, Hinterhuber $G$, Stingl $G$, Binder M. Near-fatal anaphylaxis to patent blue $\mathrm{V}$. $\mathrm{Br} J$ Dermatol. 2004;150(5):1037-8.

13. Salhab M, Al Sarakbi W, Mokbel K. Skin and fat necrosis of the breast following methylene blue dye injection for sentinel node biopsy in a patient with breast cancer. Int Semin Surg Oncol. 2005;2:26.

14. Scherer K, Studer W, Figueiredo V, Bircher AJ. Anaphylaxis to isosulfan blue and cross-reactivity to patent blue $\mathrm{V}$ : case report and review of the nomenclature of vital blue dyes. Ann Allergy Asthma Immunol. 2006;96(3):497-500.

15. Pinheiro LG, Oliveira Filho RS, Vasques $P H$, Filgueira PH, Aragão DH, Barbosa PM, et al. Hemosiderin: a new marker for sentinel lymph node identification. Acta Cir Bras. 2009;24(6):432-6.

16. Vasques PH, Alves MM, Aquino RG, Torres RV, Bezerra JL, Brasileiro LP, et al. Comparison between hemosiderin and Technetium-99 in sentinel lymph node biopsy in human breast cancer. Acta Cir Bras. 2015;30(11):785-90.

17. Albertini JJ, Lyman GH, Cox C, Yeatman T, Balducci $L, K u N$, et al. Lymphatic mapping and sentinel node biopsy in the patient with breast cancer. JAMA. 1996;276(22):1818-22.

18. Breslin TM, Cohen L, Sahin A, Fleming JB, Kuerer HM, Newman LA, et al. Sentinel lymph node biopsy is accurate after neoadjuvant chemotherapy for breast cancer. J Clin Oncol. 2000;18(20):3480-6.

19. Xing Y, Cormier JN, Kuerer HM, Hunt KK. Sentinel lymph node biopsy following neoadjuvant chemotherapy: review of the literature and recommendations for use in patient management. Asian J Surg. 2004;27(4):262-7.

20. Jones JL, Zabicki K, Christian RL, Gadd MA, Hughes KS, Lesnikoski BA, et al. A comparison of sentinel node biopsy before and after neoadjuvant chemotherapy: timing is important. Am J Surg. 2005;190(4):517-20.

21. Cox CE, Cox JM, White LB, Stowell NG, Clark $J D$, Allred $N$, et al. Sentinel node biopsy before 
neoadjuvant chemotherapy for determining axillary status and treatment prognosis in locally advanced breast cancer. Ann Surg Oncol. 2006;13(4):483-90.

22. Papa MZ, Zippel D, Kaufman B, Shimon-Paluch $S$, Yosepovich A, Oberman B, et al. Timing of sentine lymph node biopsy in patients receiving neoadjuvant chemotherapy for breast cancer. J Surg Oncol. 2008;98(6):403-6.
Received in: 16/08/2017

Accepted for publication: 17/09/2017

Conflict of interest: none.

Source of funding: none.

Mailing address:

Luiz Gonzaga Porto Pinheiro

E-mail: luizgporto@uol.com.br 